\title{
Neck Dissection in Patients with Oral Squamous Cell Carcinoma in Dharmais Hospital, Jakarta
}

\section{Denni J. Purwanto1, Jauhari 0. Reuwpassa1, Asri C. Adisasmita², Muchlis Ramli ${ }^{3}$, Ratna Djuwita ${ }^{2}$, Nurhayati A. Prihartono ${ }^{2}$, Samuel J. Haryono ${ }^{1}$, Nurtami Soedarsono4, Rahmi Amtha5, and Lenny Sari ${ }^{6}$}

${ }^{1}$ Surgical Oncologist Department, Dharmais National Cancer Hospital, Jalan S. Parman Kav 84-86 Slipi, West Java

²Epidemiology Department, Public Health Faculty, University of Indonesia

3Surgical Oncologist Department, Cipto Mangunkusumo Hospital, Jakartad

${ }^{4}$ Faculty of Dentistry, University of Indonesia, Jakarta

5 Faculty of Dentistry, Trisakti University, Jakarta

${ }^{6}$ Department of Anatomy Pathology, Dharmais National Cancer Hospital, Jakarta

\section{Abstract}

Oral squamous cell carcinoma (OSCC) is one of the rarest cancers worldwide. In

Corresponding Author:

Denni J. Purwanto

dennijoko@gmail.com

Jauhari O. Reuwpassa

okareuwpassa@gmail.com

Samuel J. Haryono

samuelharyono@yahoo.com

Received: 21 January 2018

Accepted: 8 April 2018

Published: 17 May 2018

Publishing services provided by Knowledge E

(a) Denni J. Purwanto et al. This article is distributed under the terms of the Creative Commons Attribution License, which permits unrestricted use and redistribution provided that the original author and source are credited.

Selection and Peer-review under the responsibility of the 2nd International Meeting of Public Health 2016 Conference Committee.

\section{G OPEN ACCESS} Indonesia, the incidence is less than five thousands per year, and the mortality rate is almost 50\%. More than 50\% patients with OSCC have lymph node metastasis; the proportion of occult metastasis is $24-42 \%$. Those with lymph node metastatis have the worst possibility of survival. This study aimed to estimate the survival of OSCC patients with neck dissections. We conducted a retrospective cohort study of 78 patients with OSCC who were treated in Dharmais National Cancer Hospital between 1 January 2003 and 31 January 2013. The three years survival rate post diagnosis, post neck dissection was calculated using Kaplan -Meier survival curves and statistically tested using a log-rank test. Cox proportional hazard models were applied to assess the prognostic significance of neck dissections. Of the total patients in this study ( $n=78), 53.8 \%$ of patients had surgery. Of patients who underwent surgery, $71.4 \%$ had a neck dissection surgery. These patients were in either early or advanced stages of cancer. Overall survival showed that patients who received neck dissections had better survival rates $(58.2 \%)$ than patients who did not receive neck dissection (32.2\%). Stratification at every stage of cancer (I, II, III, and IV) showed better survival in patients with neck dissections. The risk of patients without neck dissections is higher than patient with neck dissection to die, Hazard Ration(HR)=2.19 ( $\mathrm{Cl} 95 \%$ 1.04-4.62, $\mathrm{p}=0.028)$. Adequate neck dissection surgery increases chances of survival in patients with OSCC.

Keywords: Neck Dissection, Squamous Cell Carcinoma, Oral Cancer, Survival 


\section{INTRODUCTION}

Therapies can improve survival in those with oral squamous cell carcinoma (OSCC). Surgery is a successful cancer therapy with neck dissection often yielding satisfactory results. However, therapy fails for primary tumors in almost half of cases despite $90 \%$ of patients having a clear margin [2]. Other therapies are adjuvant radiotherapy and chemotherapy. Patients with metastatic lymph nodes have a recurrence risk of $62 \%$ and a survival rate of $27 \%$ if they are not given adjuvant radiotherapy after surgery [6].

Removing lymph nodes is an important factor to achieve a positive therapy result in OSCC. However, the benefit of a neck dissection is still unknown, because neck dissections mostly happen for advanced stages [3]. This study aimed to estimate the survival of OSCC patients with neck dissections.

\section{METHODS}

\subsection{Study Design}

This paper was part of a larger study on HPV, P16, EGFR and VEGF expression and margin status and neck dissection as prognostic factors of three years survival patients post diagnosis with OSCC in Dharmais Hospital. After ethical approval by the Committee of Medical Research Ethics of the Dharmais National Cancer Hospital (No. KEPK/041/X/2015) and the Committee of Ethical Research Public Health (No. 250/ UN2.F10/PPM.00.02/2015), we performed a retrospective cohort study. A total 78 patients were assessed. Patients who were eligible must have had oral cancer and squamous carcinoma cell confirmed by a histology examination. Patients whose cancer stage could not be determined and who did not have formalin-fixed, paraffinembedded (FFPE) tissues available were excluded from the study.

\subsection{Statistical analysis}

The study design was to determine the three year overall survival post diagnosis of OSCC patients in Dharmais National Cancer Hospital. Independent variables included age, sex, stage, differentiation, surgery, neck dissection, margin status, chemotherapy 
and radiotherapy. The comparison of OSCC patient survival was described by a KaplanMeier curve and significance was determined using a log rank test. A hazard ratio (HR) was calculated using a Cox semiparametric proportional hazards model.

\section{RESULTS}

From 2003 to 2013, we had analyzed 78 patients from 266 patients. The distribution of demographic data is shown in Table 1. The average age was 47 years old (range 19-78 years old). Patients over 40 years old made up $64.1 \%$ of the sample and were mostly male. The proportion of advance stage OSCC was $73.1 \%$ with well differentiation of $59.0 \%$. There were 42 patients who received surgery, most of whom (30/42) received a neck dissection. The remaining patients received chemotherapy (47.4\%) or radiotherapy (50\%).

Kaplan-Meier estimated the three years overall survival post diagnosis was $42.5 \%$ (Fig.1). Of the 78 patients, three year survival patients post diagnosis with neck dissection was $58.2 \%$ and survival with no neck dissection was $32.2 \%$. The survival rate of those with neck dissections was significantly higher $(p=0.030)$. In this group, the HR was 2.197 ( $95 \% \mathrm{Cl} 1.046-4.615)$. When stratified by surgery status $(n=42)$, the group that received neck dissections survived longer than the group that did not receive neck dissections, with $58.2 \%$ and $34.4 \%$ survival rate respectively, but it's not statistically significant $(p=0.276)$. The HR was 1.760 (95\% Cl 0.636-4.870). After adjusting the variables age, sex, differentiation, chemotherapy and radiotherapy, the multivariate analysis (Table 3 ) showed that the neck dissection group had better survival rates than the group with no neck dissections (HR = 1.795) (table 2 ).

\section{DISCUSSION}

Surgery is the main therapy to treat solid tumors. According to the Indonesia Society of Surgical Oncologist [4], every surgery should reach radical neck dissection and free margin. Over the years, there have been controversies about whether radical neck dissection should or should not be given to patients. A study by Wang et al. (2013) showed that patients with lymph node dissection, adjuvant chemotherapy or local excision, had a better prognosis compared with patients with no lymph node dissection [5]. Yuen et al. (1997) found that patients with elective neck dissections had an increased survival rate compared to those without [7]. D'Cruz et al. (2015) found that patients with early stage cancer who elected for radical neck dissection had a $12.5 \%$ 
TABLE 1: Characteristics of patient with OSCC in Dharmais Hospital.

\begin{tabular}{|c|c|c|}
\hline Variable & $\mathrm{F}$ & $\%$ \\
\hline \multicolumn{3}{|l|}{ Age } \\
\hline$\leq 40$ years & 28 & 35.6 \\
\hline$>40$ years & 50 & 64.1 \\
\hline \multicolumn{3}{|l|}{ Sex } \\
\hline Male & 47 & 60.3 \\
\hline Female & 31 & 39.7 \\
\hline \multicolumn{3}{|l|}{ Stage } \\
\hline$|-| \mid$ & 21 & 26.9 \\
\hline III-IV & 57 & 73.1 \\
\hline \multicolumn{3}{|c|}{ Differentiation } \\
\hline Good & 46 & 59.0 \\
\hline Poor & 31 & 39.7 \\
\hline Unknown & 1 & 1.3 \\
\hline \multicolumn{3}{|l|}{ Surgery } \\
\hline Yes & 42 & 53.8 \\
\hline No & 36 & 46.2 \\
\hline \multicolumn{3}{|c|}{ Neck Dissection } \\
\hline Yes & 30 & 38.5 \\
\hline No & 48 & 61.5 \\
\hline \multicolumn{3}{|l|}{ Margin Status } \\
\hline Free Margin & 37 & 47.4 \\
\hline Close Margin & 41 & 52.6 \\
\hline \multicolumn{3}{|c|}{ Chemotherapy } \\
\hline Yes & 37 & 47.4 \\
\hline No & 41 & 52.6 \\
\hline \multicolumn{3}{|l|}{ Radiotherapy } \\
\hline Yes & 39 & 50 \\
\hline No & 39 & 50 \\
\hline
\end{tabular}

TABLE 2: Univariate Cox semiparametric proportional hazard model.

\begin{tabular}{l|c|c|}
\hline Variable & Hazard ratio $(95 \% \mathrm{Cl})$ & P value \\
\hline Neck Dissection $(n=78)$ & 1.00 & \\
\hline Yes & $2.197(1.046-4.615)$ & 0.038 \\
\hline No & & \\
Neck Dissection $(n=42)$ & 1.00 & \\
Yes & $1.760(0.636-4.870)$ & 0.276 \\
\hline No &
\end{tabular}

better chance of survival, a reduced risk of death (by $36 \%$ ), and a reduced recurrence rate (by $55 \%$ ) compared with patients with therapeutic neck dissections [1]. Our study 

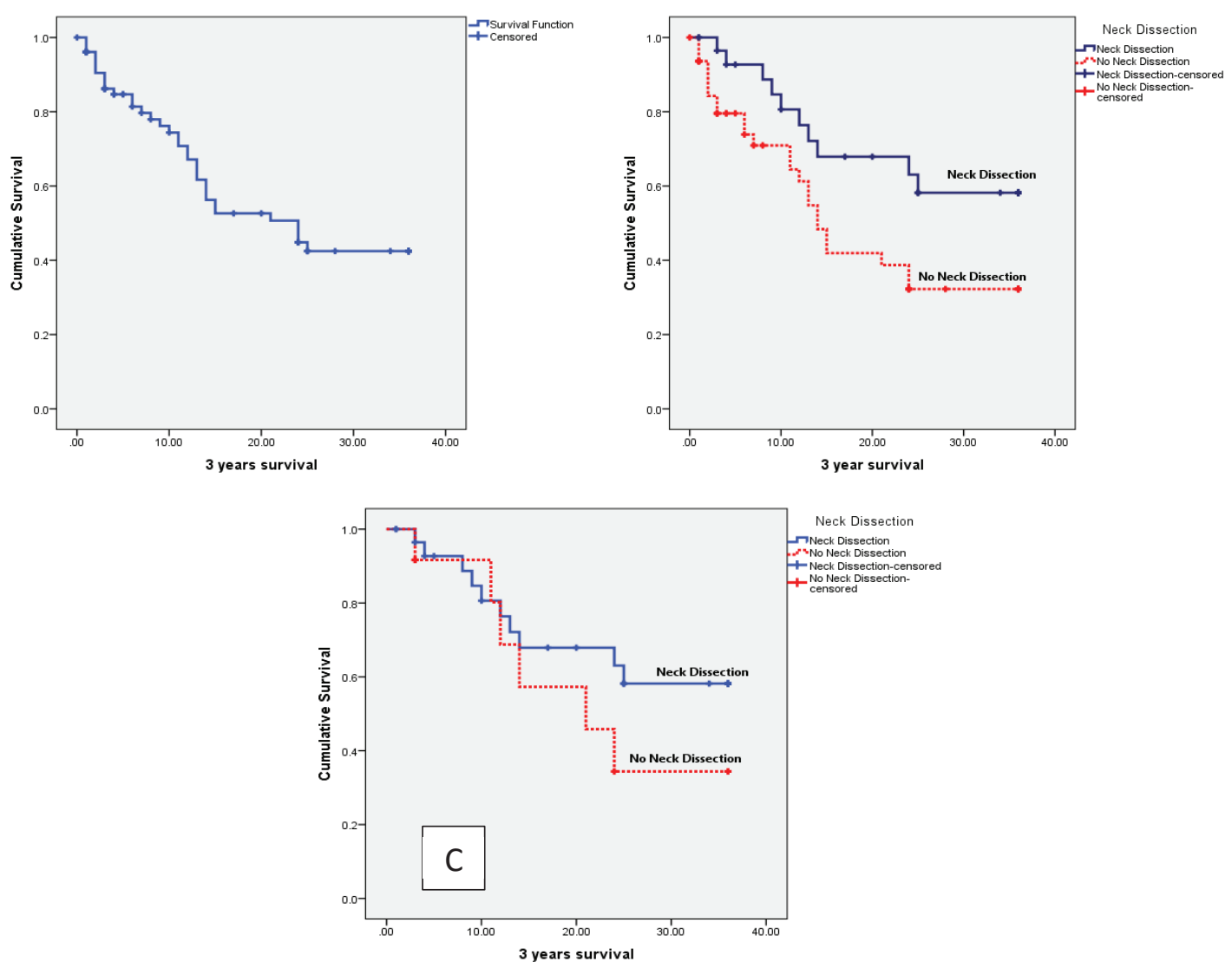

Figure 1: (A) Overall survival curve. (B) Survival curve for OSCC patients ( $n=78$ ). (C) Survival curve for OSCC patients after stratified by surgery $(n=42)$.

had the same results as these studies. Patients with neck dissections had significantly higher survival rates. However, patients with early stages of cancer (both I and II) had the same results. The group that got neck dissection surgery had better survival.

TABLE 3: Multivariate Cox regression overall survival.

Variables
Sex (Male vs Female)
Neck Dissection (Yes vs No)
Age (<=40 vs >40)
Differentiation (poor vs good)
Radiotherapy (yes vs no)
Chemotherapy (yes vs no)

\begin{tabular}{|c|c|}
\hline Hazard ratio $\mathrm{Cl} 95 \%$ & $\mathrm{p}$ value \\
\hline $0.530(0.242-1.159)$ & 0.112 \\
\hline $0.557(0.249-1.246)$ & 0.154 \\
\hline $2.122(0.975-4.622)$ & 0.058 \\
\hline $1.672(0.837-3.340)$ & 0.145 \\
\hline $0.445(0.215-0.920)$ & 0.029 \\
\hline $1.925(0.891-4.157)$ & 0.096 \\
\hline
\end{tabular}

Other studies have found that more than $50 \%$ patients with OSCC have metastatic lymph nodes positively confirmed by histology. Metastatic lymph nodes are poor prognostic factors in OSCC. In many cases also found occult metastatic lymph node, the numbers vary from $24-42 \%$. The therapy for this condition was radical neck dissection with lymph node level I-IV [2]. 
Due to the controversies regarding the efficacy of neck dissection, more studies are needed to assess the proper therapy in oral cancer develop. Many researchers suggest a sentinel node biopsy to be used in oral cavity cancer. While this method has a less clear interpretation compared to applied melanoma, the technique is promising. The advantage of sentinel node biopsy is a reduction of morbidity in the absence of a neck dissection, and the technique has proven worthwhile and accurate [3].

\section{CONCLUSIONS}

We suggested that OSCC patients should be treated with neck dissections to improve likelihood of survival. In the future, the combination of neck dissection and sentinel node biopsy will lead to a better survival and reduce morbidity.

\section{ACKNOWLEDGEMENTS}

The authors would like to thank to all of the Head and Neck team at the Dharmais National Cancer Hospital.

\section{References}

[1] D'Cruz, Anil K; Vaish, Richa; Kapre, Nethi; et al. 2015. Elective Versus Therapeutic Neck Dissection in Node-Negative Oral Cancer. The New England Journal of Medicine. 373. August 521-529.

[2] Kowalski LP and Sanabria A. 2007. Elective Neck Dissection in Oral Carcinoma: A Critical Review of the Evidence. Acto Otolarhingologica Italica, 27: 113-117.

[3] Miles BA and Myers LL. 2009. Advance Oral Cavity Cancer in Practical Head and Neck Oncology. Edited by Guy J. Petruzzelli. Plural Publishing Inc.

[4] Reskoprawiro, Sunarto, et al. 2004. Protokol Penatalaksanaan Kanker Rongga Mulut". In Protokol Peraboi edited by Zafiral A. Albar, Didid Tjindarbumi, Muchlis Ramli, Pisi Lukito, Sunarto Reksoprawiro, Djoko Handojo, Idral Darwis, Drajat R.Suardi, and Dimyati Achmad, 49-72. Bandung: Perhimpunan Ahli Bedah Onkologi Indonesia.

[5] Wang B, Zhang S, Yue K and Wang X-D. 2013. The Recurrence and Survival of Oral Squamous Cell Carcinoma: A Report of 275 Cases. Chinese Journal of Cancer, 31.11, 614618.

[6] Yuen APW, Lam KY, Chan ACL, Wei WI, Lam LK, Ho WK, et al. 1999. Clinicopathological Analysis of Elective Neck Dissection for No Neck of Early Oral Tongue Carcinoma. The 
American Journal of Surgery, 177: 90-92.

[7] Yuen APW, Wei WI, Wong YM, Tang KC. 1997. Elective Neck Dissection Versus Observation in the Treatment of Early Oral Tongue Carcinoma. Head \& Neck, October 583-588. 